\title{
Co-catalyst free Titanate Nanorods for improved Hydrogen production under solar light irradiation
}

\author{
N LAKSHMANA REDDY, D PRAVEEN KUMAR and M V SHANKAR* \\ Nanocatalysis and Solar Fuels Research Laboratory, Department of Materials Science and Nanotechnology, \\ Yogi Vemana University, Vemanapuram, Kadapa 516 003, Andhra Pradesh, India \\ e-mail: shankar@yogivemanauniversity.ac.in
}

MS received 14 December 2015; revised 1 February 2016; accepted 17 February 2016

\begin{abstract}
Harnessing solar energy for water splitting into hydrogen $\left(\mathrm{H}_{2}\right)$ and oxygen $\left(\mathrm{O}_{2}\right)$ gases in the presence of semiconductor catalyst is one of the most promising and cleaner methods of chemical fuel $\left(\mathrm{H}_{2}\right)$ production. Herein, we report a simplified method for the preparation of photo-active titanate nanorods catalyst and explore the key role of calcination temperature and time period in improving catalytic properties. Both as-synthesized and calcined material showed rod-like shape and trititanate structure as evidenced from crystal structure and morphology analysis. Notably, calcination process affected both length and diameter of the nanorods into shorter and smaller size respectively. In turn, they significantly influenced the band gap reduction, resulting in visible light absorption at optimized calcination conditions. The calcined nanorods showed shift in optical absorption band edge towards longer wave length than pristine nanorods. The rate of hydrogen generation using different photocatalysts was measured by suspending trititanate nanorods (in the absence of co-catalyst) in glycerol-water mixture under solar light irradiation. Among the catalysts, nanorods calcined at $250^{\circ} \mathrm{C}$ for 2 hours recorded high rate of $\mathrm{H}_{2}$ production and stability confirmed for five cycles. Photocatalytic properties and plausible pathway responsible for improved $\mathrm{H}_{2}$ production are discussed in detail.
\end{abstract}

Keywords. Water splitting; hydrogen production; photocatalysis; glycerol; nanorods

\section{Introduction}

Industrial and domestic activities have severely damaged the earth eco-system and the present situation warranted technology up-gradation and innovative developments for sustainable future. Intensive research has been carried out in alternative energy sector to replace fast depleting non-renewable fossil fuels. Hydrogen $\left(\mathrm{H}_{2}\right)$ production via photocatalytic water splitting process is reported as the best alternative and renewable source of $\mathrm{H}_{2}$ production and emits eco-friendly byproducts e.g., oxygen. ${ }^{1-5}$ Use of natural resources, like solar light and water paves the way for sustainable development. Among the photocatalysts developed for $\mathrm{H}_{2}$ production by water splitting, $\mathrm{TiO}_{2}$ based, one dimensional (1-D) nanostructures are of greater interest due to their interesting opto-electrical properties, unidirectional flow of electrons due to electron confinement which is advantageous for photocatalytic applications. ${ }^{6-9}$ In 1$\mathrm{D} \mathrm{TiO}_{2}$ nanostructures, the trititanate nanorod (TNR) attracts much attention owing to their higher stability, better crystallanity and presence of long axis to absorb incident light enabling nanorodsas suitable candidate for photocatalytic water splitting and dye

\footnotetext{
*For correspondence
}

sensitized solar cells (DSSCs) applications. ${ }^{10-13}$ Literature reports revealed that performance of photocatalysts was highly influenced by several factors such as crystal structure, particle size, particle shape, method of synthesis and post synthesis calcination process. ${ }^{14,15}$ Hydrothermal method is known as simple and ecofriendly method widely used for synthesis of 1-D nanostructures of $\mathrm{TiO}_{2}$ as it shows high yield at low temperature. ${ }^{16-18}$ The activity of photocatalyst was influenced by experimental parameters like presence of co-catalyst, reaction temperature and duration, solution $\mathrm{pH}$, type of hole scavengers, nature of salt, etc. In addition, post-synthesis process like calcination temperature and duration improves the crystallinity of the $\mathrm{TiO}_{2}$ nanorods which in turn influence the activity of the photocatalysts. ${ }^{15}$ We have been developing several $\mathrm{TiO}_{2}$ materials and their nanocomposite photocatalysts demonstrated high activity for $\mathrm{H}_{2}$ production under solar light irradiation. ${ }^{19-24}$ Based on our expertise in synthesis and application of Ti-O based nanostructures, they were suitably functionalized for efficient water purification in mixed matrix membranes, ${ }^{25}$ an excellent solid-acid catalyst for rapid synthesis of one-pot multi-component synthesis ${ }^{26,27}$ and a novel approach to nanotheraphy for autoimmune diseases. ${ }^{28}$ 
In the present work, cheap and non-photoactive commercial $\mathrm{TiO}_{2}$ was used as the starting material for synthesis of lab-scale, photoactive titanate nanorods (TNR). They were frequently used to study photocatalytic decontamination of organic pollutants in water with some noble metal or metal oxide cocatalyst. ${ }^{14,29-32}$ But to the best of our knowledge, only a few reports exist on unmodified and co-catalyst-free trititanate nanostructures for $\mathrm{H}_{2}$ production. For example, Liu et al., demonstrated photocatalytic $\mathrm{H}_{2}$ evolution $\left(220 \mu \mathrm{mol} . \mathrm{h}^{-1} \cdot \mathrm{g}_{\text {cat }}^{-1}\right)$ using commercial biphasic anatase-rutile $\mathrm{TiO}_{2}$ nanopowder without use of cocatalyst. ${ }^{33}$ Another report revealed the open circuit $\mathrm{H}_{2}$ production from black $\mathrm{TiO}_{2}$ nanotubes $\left(7 \mu \mathrm{mol} . \mathrm{h}^{-1}\right.$. $\left.\mathrm{g}_{\text {cat }}^{-1}\right){ }^{34}$ Chuangchote and co-workers explained synthesis of electrospun $\mathrm{TiO}_{2}$ nanofibers and tested its performance for photocatalytic $\mathrm{H}_{2}$ evolution $\left(54 \mu \mathrm{mol} . \mathrm{h}^{-1}\right.$. $\left.\mathrm{g}_{\text {cat }}^{-1}\right){ }^{35}$ The present study exploits the effect of calcination temperature and time period to improve $\mathrm{H}_{2}$ production using glycerol as sacrificial hole scavenger in the absence of any co-catalysts.

\section{Experimental}

\subsection{Synthesis of Titanate nanorods}

All the chemicals used for the present work are of analytical grade. Titanate nanorods were synthesized by hydrothermal method with slight modifications to the earlier report. ${ }^{10} \mathrm{In}$ a typical process $4 \mathrm{~g}$ of commercial $\mathrm{TiO}_{2}$ (Merck-LAB, India) was suspended in $200 \mathrm{~mL}$ of $10 \mathrm{M} \mathrm{NaOH}$ solution and magnetically stirred for 1 h. The obtained milk-white slurry was transferred into $250 \mathrm{~mL}$ capacity stainless steel autoclave and sealed for hydrothermal treatment at $200^{\circ} \mathrm{C}$ for $24 \mathrm{~h}$. Then, autoclave was allowed for natural cooling, and obtained precipitate was thoroughly washed with dilute $\mathrm{HCl}$, distilled water and ethanol, followed by drying at $80^{\circ} \mathrm{C}$ for $12 \mathrm{~h}$. The obtained nanorods were calcined at different calcination temperature for time period of 1,2 and 3 $\mathrm{h}$ in order to study the effect of post heat treatment on photocatalytic activity. The details of the photocatalysts and its nomenclature are presented below.

\subsection{Photocatalyst Characterization Techniques}

All the prepared materials were thoroughly characterized with different characterization techniques. XRD pattern was obtained by Bruker D8 Advance X-ray - diffractometer using $\mathrm{Cu} \mathrm{K} \alpha$ radiation $(\lambda=1.54 \AA$ ). Raman spectra were recorded with Raman spectrometer (LABRAM HR) operating with an excitation wavelength of $632 \mathrm{~nm}$ and power of $1 \mathrm{~mW}$. The TEM images were taken with Philips Technai G2 FEI F12 transmission electron microscope operating at $80-100 \mathrm{kV}$. Optical properties were measured in DRS - UV-Vis spectrophotometer (Varian Cary-5000).

\subsection{Solar photocatalytic experiments}

Photocatalytic experiments were conducted under solar light irradiation in sunny days between 10.00 AM and $3.00 \mathrm{PM}$. In a typical process, $5 \mathrm{mg}$ of catalyst was suspended in $5 \%$ glycerol-water mixture $(50 \mathrm{~mL})$ in $150 \mathrm{~mL}$ capacity Quartz reactor and was allowed for magnetic stirring for adsorption of glycerol and water molecules for $30 \mathrm{~min}$, followed by evacuation and nitrogen purging for $30 \mathrm{~min}$ of each step to remove gases and to simulate inert atmosphere for reduction reaction. Then, the Quartz reactor was kept under solar light irradiation for the photocatalytic $\mathrm{H}_{2}$ production via water splitting. Generated gas samples were tested at regular intervals of time using Gas Chromatograph (SHIMADZU GC2014) with thermal conductivity detector (TCD) and molecular sieve-5A by injecting the gas sample with $250 \mu \mathrm{L}$ capacity syringe.

\section{Results and Discussion}

\subsection{Characterization of Photocatalysts}

The TEM images of TNR and TNR-2 are depicted in figure 1(a-c). It reveals that overlapping of several rod-like shapes and its diameter is in the nanoscale. ${ }^{10}$ TNR and TNR-2 look like cylindrical in shape filled inside, very smooth and clean without any other contamination. Length of the TNR is about $1-4 \mu \mathrm{m}$ and

\begin{tabular}{ll}
\hline Photocatalyst & Nomenclature \\
\hline As synthesized Titanate Nanorods & TNR \\
Titanate Nanorods calcined @ $200^{\circ} \mathrm{C} / 2 \mathrm{~h}$ & TNR-1 \\
Titanate Nanorods calcined @ $250^{\circ} \mathrm{C} / 1 \mathrm{~h}$ & TNR-2-1 \\
Titanate Nanorods calcined @ $250^{\circ} \mathrm{C} / 2 \mathrm{~h}$ & TNR-2 \\
Titanate Nanorods calcined @ $250^{\circ} \mathrm{C} / 3 \mathrm{~h}$ & TNR-2-3 \\
Titanate Nanorods calcined @ $300^{\circ} \mathrm{C} / 2 \mathrm{~h}$ & TNR-3 \\
Titanate Nanorods calcined @ $400^{\circ} \mathrm{C} / 2 \mathrm{~h}$ & TNR-4 \\
\hline
\end{tabular}



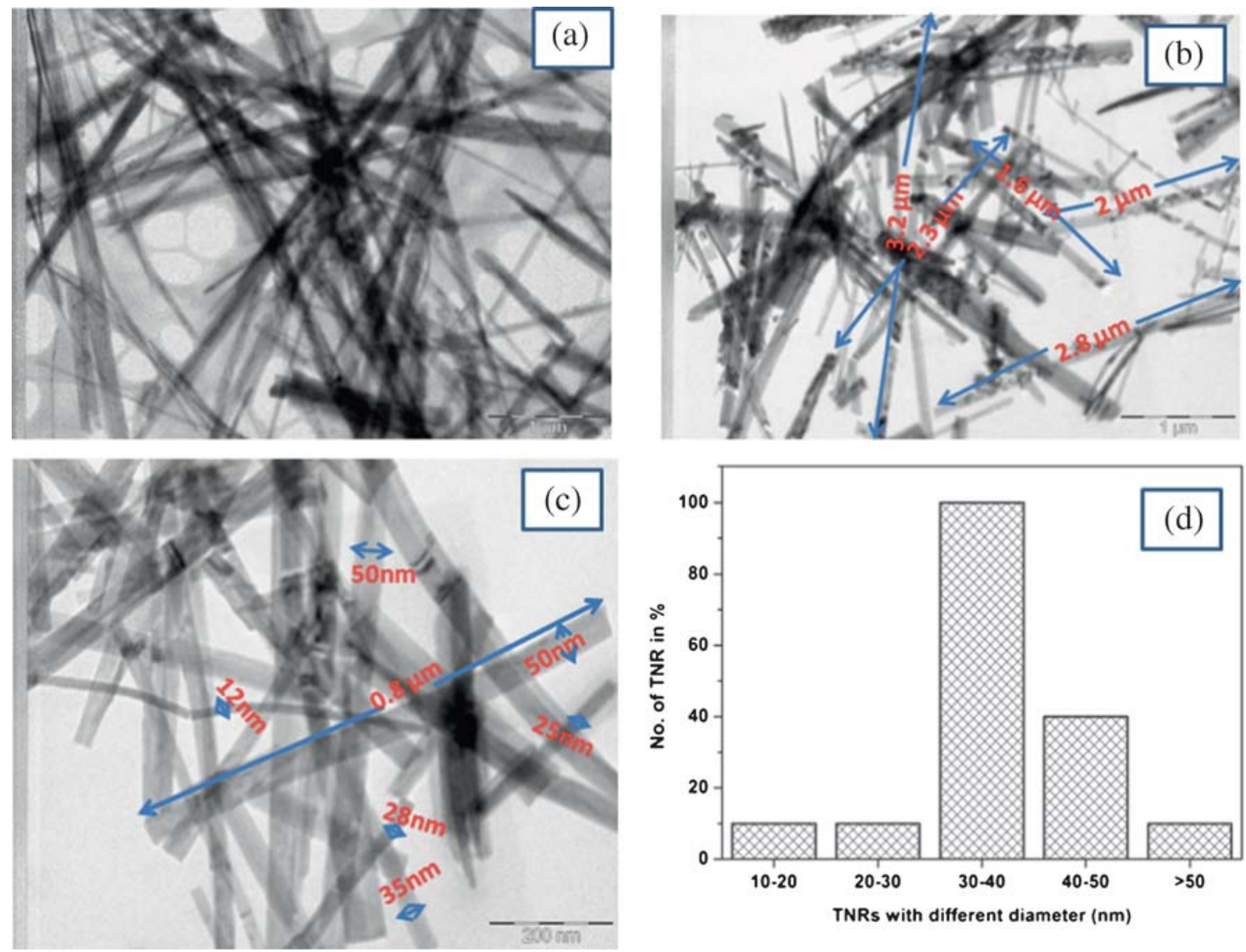

Figure 1. TEM images of (a) TNR; (b) and (c) low and high magnification images of TNR-2; (d) histogram of diameter of TNR-2.

diameter varies from 10 to $50 \mathrm{~nm}$ and uniform size is maintained throughout the length, whereas the calcined nanorods were fragmented in terms of length and diameter with thermal treatment. It is ascribed to dehydration of water molecules and agglomeration tendency of nanorods into bundles. ${ }^{20}$ The present study showed length of the nanorods is minimized compared with earlier reports; it is attributed to higher concentration of the starting material within the desired volume of $\mathrm{NaOH}{ }^{7}$ The histogram of TNR-2 is displayed in figure 2(d). It shows that more than $90 \%$ of TNR-2 has average diameter of $30-40 \mathrm{~nm}$ and the $40 \%$ of the nanorods have diameter around 40-50 $\mathrm{nm}$.

The figure 2(a) shows the XRD patterns of the as-synthesized and calcined Titanate nanorods. The as-synthesized nanorods (TNR) displayed characteristic diffraction pattern at $2 \theta=10.5,25.230 .1,34.8$, 39.1 and $48.7^{\circ}$, attributed to (001), (102), (300), (112) and (303) planes of sodium trititanate $\left(\mathrm{Na}_{2} \mathrm{Ti}_{3} \mathrm{O}_{7}\right)$ with monoclinic structures (JCPDS Card no: 31-1329). Upon thermal treatment, the $2 \theta$ peak at $10.54^{\circ}$ disappears and new peak at $2 \theta=12.82^{\circ}$ corresponding to (101) plane appeared from TNR-2 to TNR-4 besides minor shift in two theta values. Similarly, the peaks at $25.2^{\circ}$ and $30.1^{\circ}$ for TNR disappeared and new peaks at $25.59^{\circ}$ and $28.22^{\circ}$ corresponding to (011) and (111) planes appeared from TNR-2 onwards and these peaks also showed shift towards higher $2 \theta$ values. The change also affected inter planer distance and crystallinity with thermal treatments. ${ }^{37,44}$ Moreover, intensity of all the major peaks increased with thermal treatments from 200 to $400^{\circ} \mathrm{C}$ for TNR-1 to TNR-4. The above observations demonstrate that calcination process induces the crystallization and minimized crystal defects. Based on the above results, we concluded that post hydrothermal treatments like calcinations and washing process also play an important role in crystal structure and crystallinity of the materials. Papp et al. ${ }^{38}$ studied temperature effects on the structural behavior of sodium tri- and hexa-titanates and stated that high amount of $\mathrm{Na}^{+}$ ions showed stabilizing effect and thus $\mathrm{H}_{2} \mathrm{Ti}_{6} \mathrm{O}_{13}$ does not undergo structural changes. Kolen et al., ${ }^{10}$ revealed that the crystal phases of $\mathrm{Na}_{2} \mathrm{Ti}_{3} \mathrm{O}_{7}$ were unchanged up to heat treatment at $400^{\circ} \mathrm{C}$. Morgado et al. ${ }^{36}$ concluded that the concentration of $\mathrm{HCl}$ also plays a major role in the formation of crystal structure and composition.

Raman spectra of TNR and TNR-2 are displayed in figure 2(b). The characteristic vibrational modes 

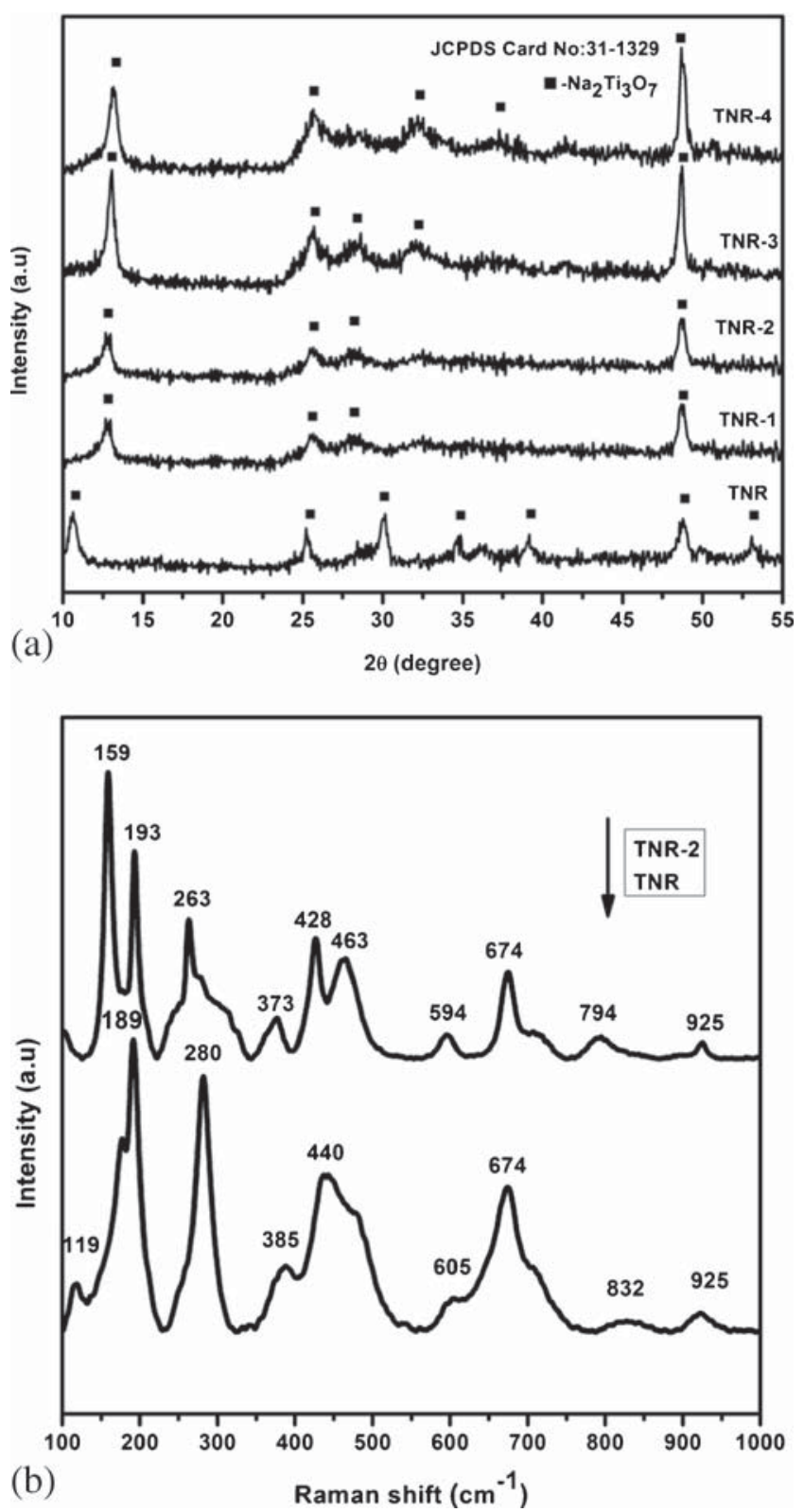

Figure 2. (a) XRD pattern of as-synthesized and calcined TNR. (b) Raman spectrum of as-synthesized and calcined TNR.

appeared for TNR at 119, 280, 440, 674 and 925 $\mathrm{cm}^{-1}$ and for TNR-2, the observed shifts at 159, 193, $373,428,463,674$, and $925 \mathrm{~cm}^{-1}$ reveal $\mathrm{Na}_{2} \mathrm{Ti}_{3} \mathrm{O}_{7}$ with monoclinic structure. These data are in accordance with earlier reports. ${ }^{10,39}$ Particularly, the band at $280 \mathrm{~cm}^{-1}$ for TNR corresponds to Na-O-Ti stretching vibrations ${ }^{40}$ and the bands at 159 and $193 \mathrm{~cm}^{-1}$ of TNR-2 corresponds to Na-O-Ti bending modes ${ }^{43}$ and it clearly demonstrates that formed nanostructure is $\mathrm{Na}_{2} \mathrm{Ti}_{3} \mathrm{O}_{7}$. For TNR and TNR-2, we can find that most peaks related to Ti-O based structure are almost the same. It demonstrates that it does not undergo structural changes. Minor absorption shift in bands of TNR at 189 and $440 \mathrm{~cm}^{-1}$ showed doublets at 159,193 and $428,463 \mathrm{~cm}^{-1}$, respectively, after thermal treatments, and the changes indicate that calcined nanorods showed phase shift as evidenced by XRD results. For TNR and TNR-2, the relative intensities varied. The band at 674 $\mathrm{cm}^{-1}$ for TNR-2 represented Ti-O-Ti stretching vibration in edge-shared $\mathrm{TiO}_{6}$ octahedral. ${ }^{40}$ The changes in the relative intensities of TNR and TNR-2 are caused by dehydration of water molecules in the lattice structures during thermal treatment and these observations are in tune with the XRD results.

Optical properties of the titanate nanorods were examined using DRS-UV-Vis spectrophotometer. The absorption spectra (figure 3(a)) revealed that with respect to calcination temperature the characteristics of absorption by nanorods (TNR-2: $385 \mathrm{~nm}$, TNR-3: 388 nm, TNR-4: $391 \mathrm{~nm}$, TNR: $364 \mathrm{~nm}$ ) showed red shift. The band gap values for all the photocatalysts were calculated by using Kubelka-Munk function by plotting
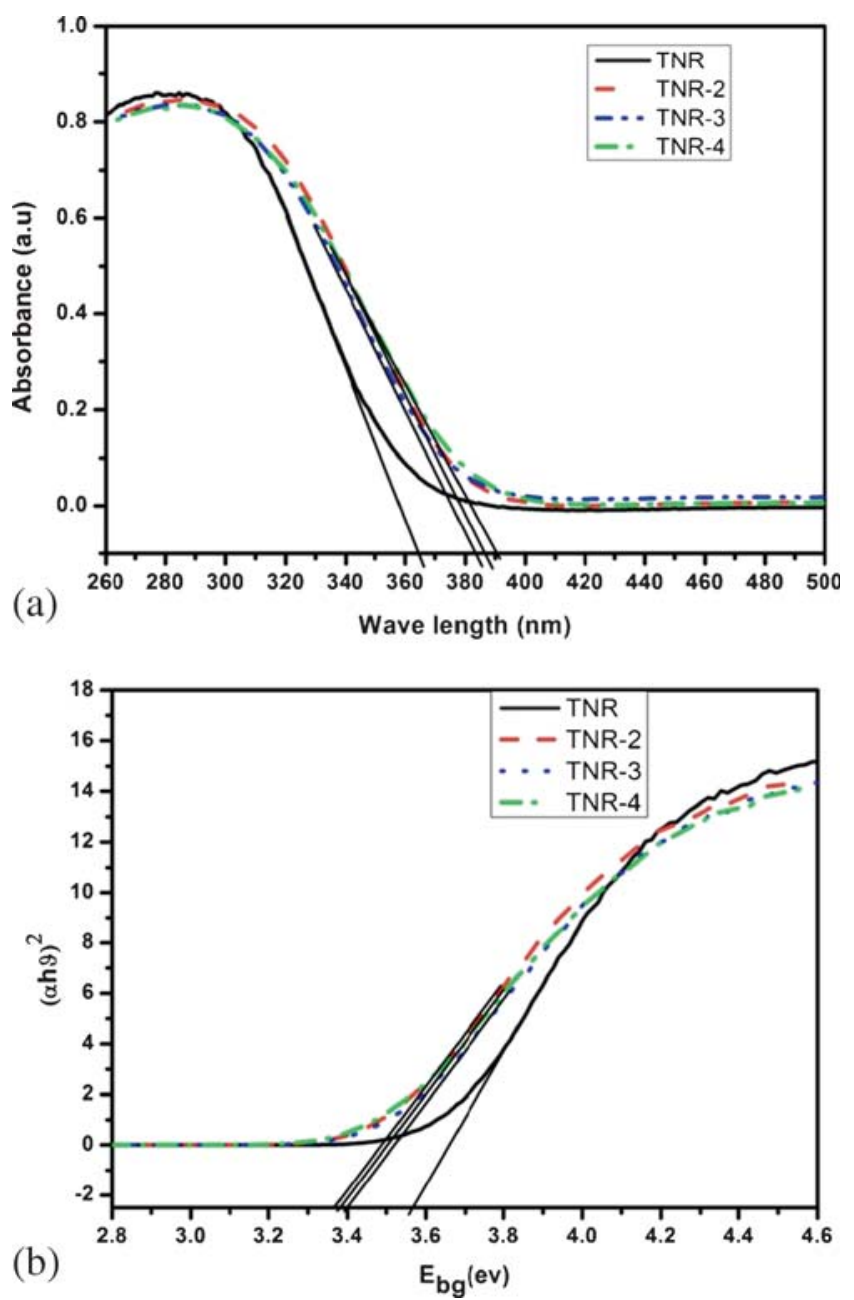

Figure 3. (a) DR UV-Vis spectra TNR catalysts; (b) Plot of transformed Kubelka-Munk function $(\alpha h \nu)^{2}$ vs. photon energy $(\mathrm{h} v, \mathrm{eV})$ for as-synthesized and calcined TNR catalysts to estimate band gap energies by linear extrapolation. 
a graph between $(\alpha \mathrm{h} v)^{2}$ vs. photon energy (hv) and the plot is shown in figure 3(b) . Decrease in band gap value from 3.58 to $3.33 \mathrm{eV}$ for TNR and TNR4 , respectively, was noted and similar changes were reported in literature. ${ }^{39,41}$ The relative decrease in band gap of the calcined titanate nanorods strongly affected surface and optical properties. ${ }^{36}$ The red shift in absorption is attributed to improvement of crystallanity via de-hydroxylation of surface hydroxyl groups and desorption of physisorbed water molecules which result in shorter and smaller size of nanorods.

\subsection{Photocatalytic hydrogen production}

The photocatalytic activity of the prepared Titanate nanorods was tested under direct solar light irradiation for $4 \mathrm{~h}$. Figure 4(a) displays the effect of calcination temperature (from 200 to $400^{\circ} \mathrm{C}$ ) on the rate of photocatalytic $\mathrm{H}_{2}$ production. It is evident that TNR2 (calcined at $250^{\circ} \mathrm{C}$ ) showed the highest rate of $\mathrm{H}_{2}$

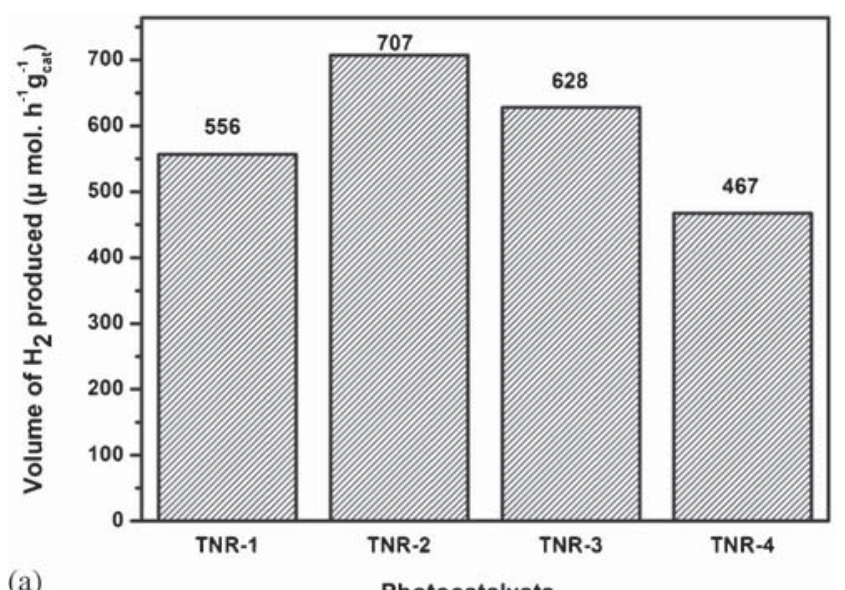

(a)

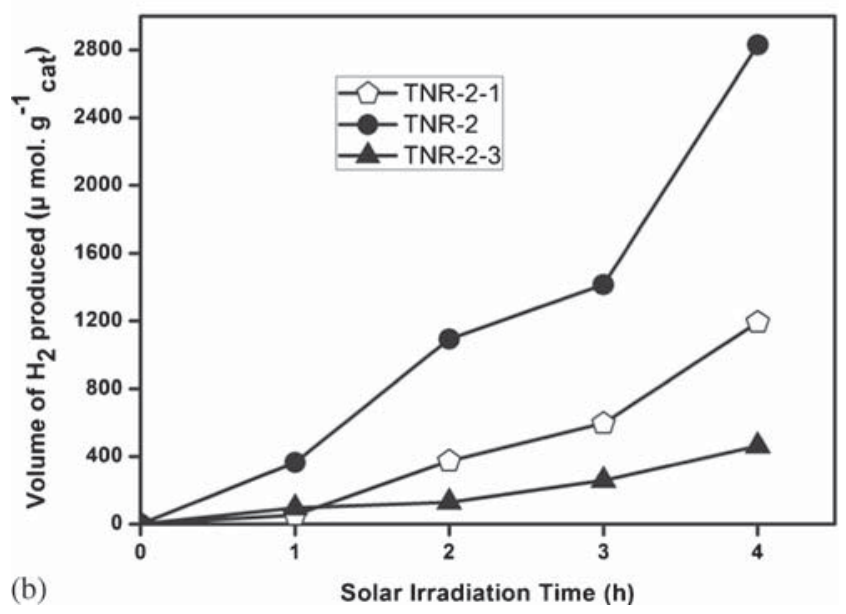

Figure 4. (a). Effect of calcination temperature for photocatalytic $\mathrm{H}_{2}$ production in aqueous glycerol solution under solar light irradiation. (b). Effect of calcination duration for photocatalytic $\mathrm{H}_{2}$ production in aqueous glycerol solution under solar light irradiation. production of $707 \mu \mathrm{mol} . \mathrm{h}^{-1} \cdot \mathrm{g}_{\text {cat }}^{-1}$ in aqueous glycerol solution. The high catalytic activity as mentioned above is attributed to one dimensional flow of photogenerated charge carriers and facile electron donating nature of glycerol facilitated effective oxidation and reduction reactions. The lower catalytic activity is recorded for TNR-1 photocatalyst and is assigned to lower catalytic active sites, whereas low activity of TNR-3 and TNR-4 catalysts is assigned to limited availability of photogenerated charge carriers at catalyst surface for the reaction. In this study, at lower catalyst calcination temperature, the poor crystallinity noticed in X-ray diffraction pattern, is a result of fewer active sites available for the catalytic reaction. Moreover, temperature above optimal calcination tends to form particle-particle agglomeration of catalyst and diminished the surface area and active sites of the catalyst. ${ }^{45}$ Yoshida et al. ${ }^{37}$ explained that experimental parameters like calcination temperature and time strongly influence the efficiency of the photocatalyst. Recent reports emphasized that the calcination temperature significantly affects the crystallanity and alter the shape of the catalytic material. ${ }^{36,42}$

The prepared TNRs were calcined at different calcination duration viz., $250^{\circ} \mathrm{C} / 1 \mathrm{~h}, 250^{\circ} \mathrm{C} / 2 \mathrm{~h}$ and $250^{\circ} \mathrm{C} / 3 \mathrm{~h}$ denoted as TNR-2-1, TNR-2 and TNR-23 , respectively, to study the effect of calcination time. Figure 4(b), shows the TNR calcined at different calcination time versus photocatalytic $\mathrm{H}_{2}$ production. In comparison, TNR-2 showed improved $\mathrm{H}_{2}$ production than other catalysts. The TNR-2-1 showed lower activity due to lower crystallanity and whereas the lower activity for TNR-2-3 is due to agglomeration of the nanostructures at longer duration of calcination.

Recyclability tests were performed for the optimized photocatalyst (TNR-2) for 5 cycles under solar light irradiation in order to estimate the stability of the photocatalyst (figure 5). In each cycle, TNR-2 was irradiated for $4 \mathrm{~h}$, the generated gas samples were quantified

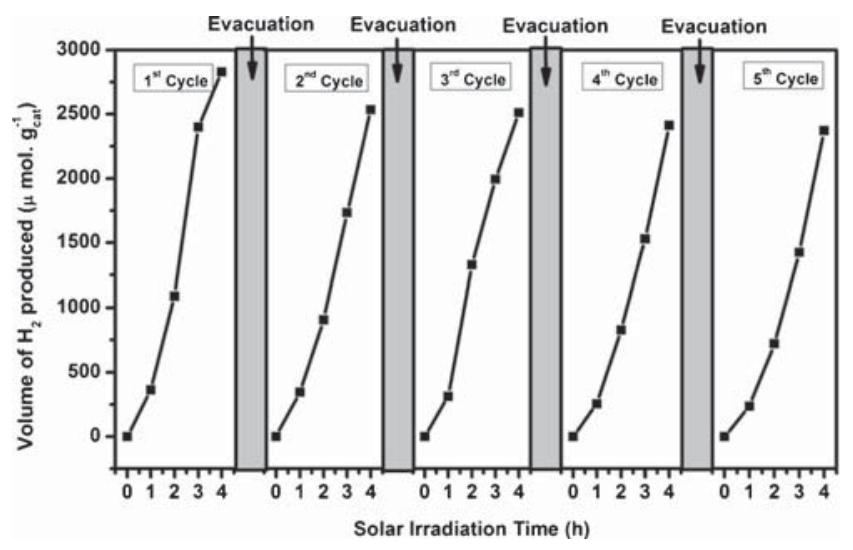

Figure 5. Recyclability of TNR-2 under solar irradiation. 


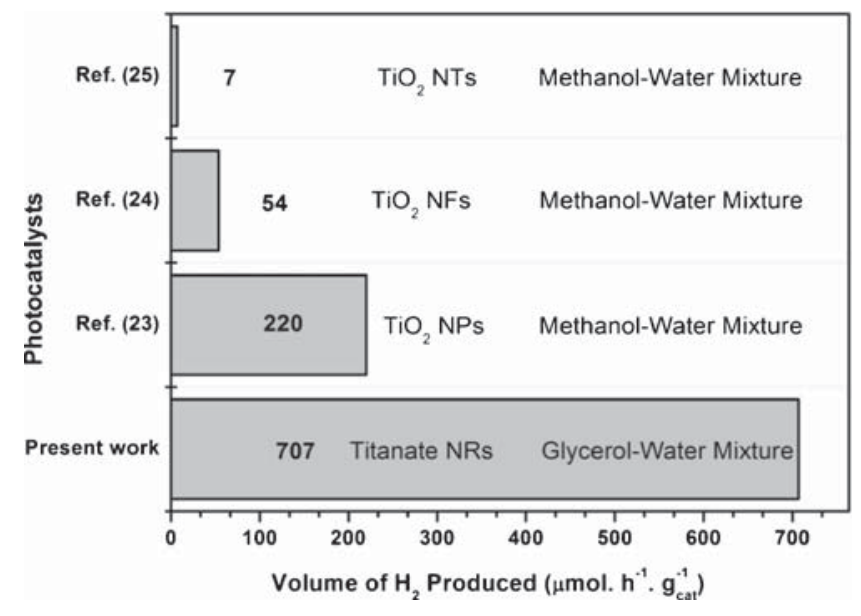

Figure 6. Comparison of solar $\mathrm{H}_{2}$ generation using $\mathrm{TiO}_{2}$ photocatalysts.

for each hour using Gas Chromatograph equipped with TCD. After $1^{\text {st }}$ cycle, the quartz reactor was evacuated to eliminate gases and purged with $\mathrm{N}_{2}$ gas for inert atmosphere and again irradiated by solar light for $2^{\text {nd }}$ cycle, and the evolved gases were again tested using gas chromatograph similar to $1^{\text {st }}$ cycle. The same procedure was followed for $3^{\text {rd }}, 4^{\text {th }}$ and $5^{\text {th }}$ cycle of experiments. In all the cycles, stable $\mathrm{H}_{2}$ generation was seen. About $83.8 \%$ of $\mathrm{H}_{2}$ generated at $5^{\text {th }}$ cycle. In $4^{\text {th }}$ and $5^{\text {th }}$ cycles, the $\mathrm{H}_{2}$ generation was slightly less, which may be due to decomposition of sacrificial agent (glycerol), and increase in the number of intermediate products in glycerol reforming process. ${ }^{46}$ These recyclability experiments reveal that our prepared titanate nanorod photocatalyst has exhibited very good stability for longer hours.
Recent reports on photocatalytic $\mathrm{H}_{2}$ generation using $\mathrm{TiO}_{2}$ nanoparticles and nanostructures without cocatalyst in presence of sacrificial reagents have been compared with the present work. Here, we used industrial byproduct glycerol as sacrificial reagent whereas others have used methanol. Figure 6 shows the photocatalytic $\mathrm{H}_{2}$ production of $\mathrm{TiO}_{2}$ nanorod-based photocatalysts. The high activity is ascribed to shape of nanorods and electron donating nature glycerol present in the aqueous solution.

Based on the experimental results, a plausible reaction mechanism is proposed. The beneficial properties of the 1-D nanostructures, such as catalytic active sites available on the surface, uni-directional flow of electrons along the axis of the nanorods, minimization of electron-hole pairs are shown in scheme 1 . When solar light irradiates the titanate nanorods, the valence band (VB) electrons get excited and transferred to the conduction band $(\mathrm{CB})$ and migrate to the surface of the 1-D nanorods and holes remain in the VB. First, oxidation reaction takes place with holes on $\mathrm{VB}$ and forms $\mathrm{H}^{+}$ ions from either water or glycerol, and these $\mathrm{H}^{+}$ions undergo reduction to $\mathrm{H}_{2}$ with photogenerated electrons at $\mathrm{CB}$ of nanorods. Alternatively, holes in VB oxidize glycerol and its intermediates into $\mathrm{H}^{+}$ions. These intermediates produce $\mathrm{H}^{+}$ions, and $\mathrm{CO}_{2}$ under prolonged light irradiation.

\section{Conclusions}

In summary, post-synthesis calcination process significantly improved the photocatalytic activity of sodium titanate nanorods prepared using hydrothermal

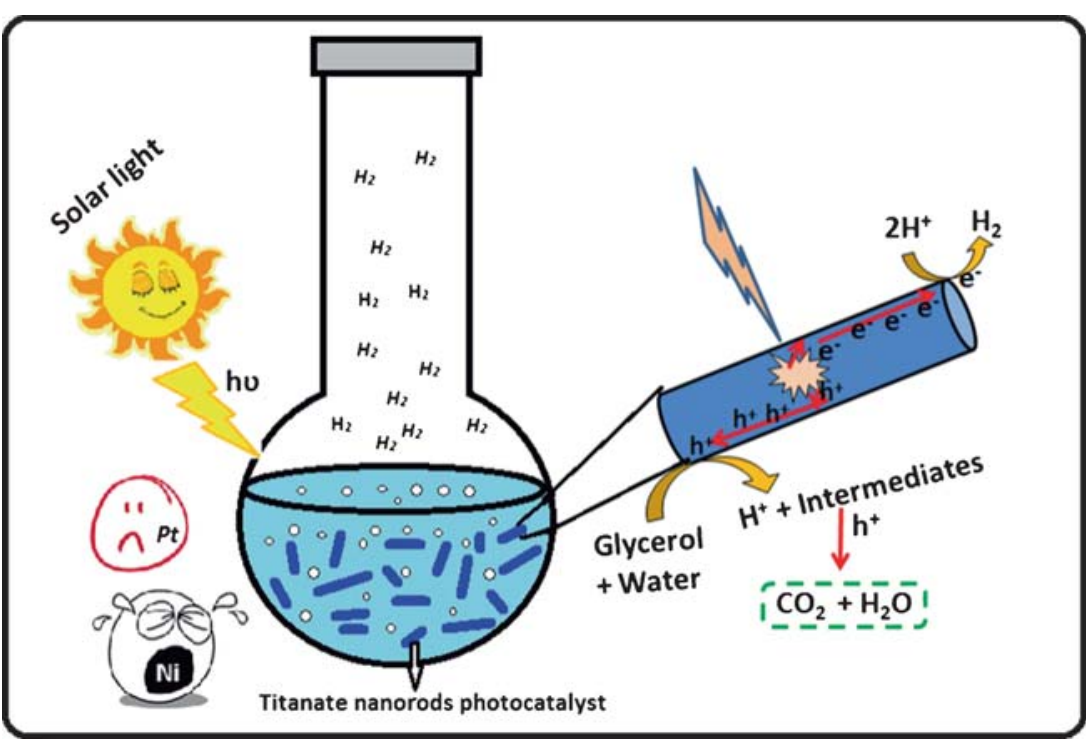

Scheme 1. Proposed reaction mechanism of titanate nanorods for photocatalytic $\mathrm{H}_{2}$ production under direct solar light irradiation. 
method. Structural analysis revealed that trititanate nanorods have layered structure and interlayer distance decreases with optimized calcination temperature and time period, which is ascribed to dehydration of water molecules. The examination of optical properties and morphology of titanate nanorods with calcination shows shift in band edge and decrease in length of nanorods. The solar photocatalytic performance studied in batch mode under ambient conditions and nitrogen atmosphere showed that the rate of hydrogen production was influenced by both calcination temperature and time period. The TNRs calcined at $250^{\circ} \mathrm{C}$ for $2 \mathrm{~h}$ (TNR-2) showed improved activity ascribed to synergetic functions of 1-D nanostructure, stable morphology with thermal treatments and minimal defect sites that lead to fast transfer of charge carriers to the surface for improved photocatalytic hydrogen generation. In the present study, the improved $\mathrm{H}_{2}$ production rate is ascribed for two major reasons: (i) One dimensional titanate nanorods catalyst effectively delocalized the photogenerated charge carriers (electron-hole) along its length but confined the movement in exterior walls of nanorods. (ii) The improved adsorption and electron donating nature of glycerol served as suitable hole scavenger for continuous production of $\mathrm{H}^{+}$ions. The present study highlighted that post-synthesis heat treatment can improve the photocatalytic performance in the absence of any co-catalyst. Moreover, the recyclability tests demonstrated the stability of the photocatalyst for 5 cycles without any significant loss in its catalytic performance. The experimental results demonstrated that glycerol undergoes photocatalytic reforming and produces $\mathrm{H}^{+}$ions instantaneously which undergoes reduction with photogenerated electrons for $\mathrm{H}_{2}$ production.

\section{Acknowledgements}

N. Lakshmana Reddy is grateful to Department of Science and Technology (DST), New Delhi [IF 131053] for financial support through INSPIRE Fellowship.

\section{References}

1. Liao C H, Huang C W and Wu J C S 2012 Catalysts 2 490

2. Chen X, Shen S, Guo L and Mao S S 2010 Chem. Rev. 1106503

3. Rajaambal S, Sivaranjani K and Gopinath C S 2015 J. Chem. Sci. 12733

4. Daya Mani A, Xanthopoulos N, Laub D and Subrahmanyam, C H 2014 J. Chem. Sci. 126967

5. Tijare S N, Bakardjieva S, Subrt J, Joshi M V, Rayalu S S, Hishita S and Labhsetwar N 2014 J. Chem. Sci. 126 517
6. Wang X, Li Z, Shi J and Yu Y 2014 Chem. Rev. 1149346

7. Lee K, Mazare A and Schmuki P 2014 Chem. Rev. 114 9385

8. Zhou W, Liu H, Boughton R I, Du G, Lin J, Wang J and Liu D 2010 J. Mater. Chem. 205993

9. Ma Y, Wang X, Jia Y, Chen X, Han H and Li C 2014 Chem. Rev. 1149987

10. Kolenko Y V, Kovnir K A, Gavrilov A I, Garshev A V, Frantti J, Lebedev O I, Churagulov B R, Van Tendeloo O G and Yoshimura M 2006 J. Phys. Chem. B 1104030

11. Lee E, Hong J Y, Kang H and Jang J 2012 J. Hazard. Mater. 21913

12. Khemthong P, Photai P and Grisdanurak N 2013 Int. J. Hydrogen Energy 3815992

13. Yan K, Wu G, Jarvis C, Wen J and Chen A 2014 Appl. Cat. B: Environ. 148281

14. Yun H J, Lee H, Joo J B, Kim N D and Yi J 2011 J. Nanosci. Nanotechnol. 111

15. Huang C W, Liao C H and Wu J C S 2013 J. Clean Energy Technol. 11

16. Hayashi H and Hakuta Y 2010 Materials 33794

17. Natarajan S, Mandal S, Mahata P, Koteswara Rao V, Ramaswamy P, Banerjee A, Kumar Paul A and Ramya K V 2006 J. Chem. Sci. 118525

18. Byrappa K and Adschiri T 2007 Prog. Cryst. Growth. Charact. Mater. 53117

19. Praveen Kumar D, Shankar M V, Mamatha Kumari M, Sadanandam G, Srinivas B and Durga Kumari V 2013 Chem. Commun. 499443

20. Praveen Kumar D, Lakshmana Reddy N, Mamatha Kumari M, Srinivas B, Durga Kumari V and Shankar M V 2014 JoCC 113

21. Praveen Kumar D, Shankar M V, Lakshmana Reddy N, Parasuramudu D, Rajarajeswari D and Durga Kumari V 2013 Solar Light Active $\mathrm{CuO} / \mathrm{TiO}_{2}$ Nanobelt Photocatalyst for Enhanced $\mathrm{H}_{2}$ Production, Proceedings of the "International Conference on Advanced Nanomaterials \& Emerging Engineering Technologies" organizaed by Sathyabama University, Chennai, India in association with DRDO, New Delhi, India. 24th-26th July 2013.

22. Praveen Kumar D, Lakshmana Reddy N, Srinivas B, Durgakumari V, Roddatis V, Bondarchuk O, Karthik M, Ikuma Y and Shankar M V 2016 Sol. Energy Mater. Sol. Cells 14663

23. Praveen Kumar D, Lakshmana Reddy N, Mamatha Kumari M, Srinivas B, Durgakumari V, Roddatis V, Bondarchuk O, Karthik M, Nepplian B and Shankar M V 2015 Sol. Energy Mater. Sol. Cells 136157

24. Mamatha Kumari M, Praveen Kumar D, Haridoss P, Durga Kumari V and Shankar M V 2015 Int. J. Hydrogen Energy 401665

25. Sumisha S, Arthanareeswaran G, Ismail A F, Praveen Kumar D and Shankar M V 2015 RSC Adv 4939464

26. Rajendra Prasad Reddy B, Vasu Govardhana Reddy P, Praveen Kumar D, Reddy B N and Shankar M V 2016 RSC Adv. 614682

27. Rajendra Prasad Reddy B, Venkata Krishna Reddy M, Vasu Govardhana Reddy P, Praveen Kumar D and Shankar M V 2016 Tetrahedron Lett. 51696

28. Sree Latha T, Dakshayani L, Praveen Kumar D, Shankar M V and Madhava Reddy C 2016 RSC Adv. 68870

29. Pu Y C, Chen Y C and Hsu Y J 2010 Appl. Cat. B: Environ. 97389 
30. Sun T, Fan J, Liu E, Liu L, Wang Y, Dai H, Yang Y, Hou W, Hu X and Jiang Z 2012 Powder Technol. 228210

31. Khan M A, Akhtar M S, Woo S I and Yang O B 2008 Catal. Commun. 101

32. Liu C, Tang J, Chen H M, Liu B and Yang P 2013 Nano Lett. 132989

33. Liu N, Schneider C, Freitag D, Venkatesan U, Reddy M V R, Hartmann M, Winter B, Spiecker E, Osvet A, Zolnhofer E M, Meyer K, Nakajima T, Zhou X and Schmuki P 2014 Angew. Chem. Int. Ed. 5314201

34. Liu N, Schneider C, Freitag D., Hartmann M, Venkatesan, U, Muller J, Spiecker E and Schmuki P 2014 Nano Lett. 143309

35. Chuangchote $\mathrm{S}$, Jitputti J, Sagawa $\mathrm{T}$ and Yoshikawa $\mathrm{S}$ 2009 ACS Appl. Mater. Interfaces 11140

36. Morgado E, Abreu M A S, Pravia O R C, Marinkovic B A, Jardim P M, Rizzo F C and Araujo A S 2006 Solid State Sci. 8888

37. Yoshida R, Suzuki Y and Yoshikawa S J 2005 Solid State Chem. 1782179
38. Papp S, Korosi L, Meynen V, Cool P, Vansant E F and Dekany I 2005 J. Solid State Chem. 1781614

39. Wu Z, Guo S, Wang H and Liu Y 2009 Electrochem. Coтmun. 111692

40. Menga X, Wang D, Liu J and Zhang S 2004 Mater. Res. Bull. 392163

41. Fu X, Leung D Y C and Chen S 2014 Cryst. Eng. Comm. 16616

42. Kiatkittipong K, Iwase A, Scott J and Amal R 2013 Chem. Eng. Sci. 93341

43. Ren N, Li R, Chen L, Wang G, Liu D, Wang Y, Zheng L, Tang W, Yu X, Jiang H, Liu H and Wu N 2012 J. Mater. Chem. 2219151

44. Zhu G N, Wang C X and Xia Y Y 2011 J. Power Sources 1962848

45. Vijayan B, Dimitrijevic N M, Rajh T and Gray K 2010 J. Phys. Chem. C 11412994

46. Bowker M, James D, Stone P, Bennett R, Perkins N, Millard L, Greaves J and Dickinson A 2003 J. Catal. 217133 